\title{
Intelectual orgânico como mediador da informação: algumas considerações acerca de um diálogo possível
}

\author{
Intellectual organic as mediator information: some considerations about a possible dialogue
}

Ciro Athayde Barros Monteiro Doutorando do Programa de Pós-Graduação em Ciência da Informação da UNESP, campus de Marília.

E-mail: cirocosmos@gmail.com

Oswaldo Francisco de Almeida Junior

Doutor em Ciências da Comunicação pela Universidade de São Paulo - USP. Professor Associado da Universidade Estadual de Londrina; Professor Titular do Programa de Pós-graduação em Ciência da Informação da Universidade Estadual Paulista Júlio de Mesquita Filho - UNESP, campus de Marilia.

E-mail: ofaj@ofaj.com.br

\section{Resumo}

A definição do conceito de mediador da informação tem sido de maneira geral, na área de Ciência da Informação, associado ao profissional da informação. No entanto, a informação é mediada por um número amplo de pessoas e de ambientes informacionais que transcendem os ambientes como as bibliotecas, os arquivos e museus, tradicionalmente pensados pela CI. Sem contestar a importância dos ambientes trabalhados no campo, o objetivo aqui posto é tecer algumas considerações acerca do conceito de profissional da informação e refletir, por meio do conceito Gramsciano de Intelectual Orgânico, acerca da ideia de mediador da informação para que possamos pensar sobre como a informação é mediada em todos os âmbitos da sociedade, ou seja, em seus vários grupos, organizações e veículos de comunicação. Por fim, é apresentado a ideia do mediador como sendo todos aqueles que atuam na sociedade, como o pastor, o padre, o jogador, o representante comunitário, o professor, o profissional da saúde, da computação, o músico, o jornalista, etc., ou seja, um Intelectual Orgânico fundamental para promover transformações sociais.

Palavras-chaves: Mediador da Informação. Intelectual Orgânico. Ciência da Informação.

\begin{abstract}
The definition of the concept of information mediator has been in general, in the field ofInformation Science, associated to the information professional. However, information is mediated by a large number of people and information environments that transcend environments such as libraries, archives and museums, traditionally thought by CI. Without objecting to the importance of the environments worked in the field, the objective here is to make some considerations about the concept of information professional and to reflect, through the Gramsciano concept of Organic Intellectual, about the idea of mediator of the information so that we can think about how Information is mediated in all spheres of society, that is, in its various groups, organizations and communication vehicles. Finally, the idea of the mediator is presented as being all those who work in society, such as pastor, priest, player, community representative, teacher, health professional, computer, musician, journalist, etc., that is, a fundamental Intellectual Intellectual to promote social transformations.
\end{abstract}

Keywords: Mediator of Information. Organic Intellectual. Information Science.

InCID: R. Ci. Inf. e Doc., Ribeirão Preto, v. 8, n. 2, p. 92-105, set. 2017/fev. 2018.

DOI: 10.11606/issn.2178-2075.v8i2p92-105 


\section{Introdução}

O conceito de mediador da informação e sua definição voltada à atuação do profissional da informação, muitas vezes associado ao bibliotecário, arquivista, museólogo, acaba por limitar as possibilidades do campo para pesquisadores da área de Ciência da Informação (CI) que pretendem trabalhar com outros ambientes informacionais, tendo em vista que o conceito de mediador da informação acaba por se restringir a estes profissionais. Nessa perspectiva surgem algumas questões como, por exemplo, de que maneira é possível refletir acerca dos demais mediadores sociais? Como trabalhar com a informação mediada em ambientes, como empresas, presídios, igrejas, escolas, hospitais, estádios de futebol, meios de comunicação, partidos, etc?

Sem negar a importância inconteste de trabalhar com as ditas três Marias ${ }^{1}$, nos propusemos a refletir acerca das possibilidades de atuação do mediador da informação nos ambientes já atuantes no campo e também nas múltiplas ambiências em que esse profissional pode atuar, rompendo com o papel de mero reprodutor de uma situação social, despertando no mediador sua função de protagonista social.

O artigo apresenta as concepções de mediador e mediação da informação trabalhada por alguns autores da área e faz algumas considerações acerca das possibilidades de contribuição do conceito de Intelectual Orgânico desenvolvido por Antônio Gramsci como subsídio para ampliar a noção de mediador da informação desenvolvida no campo da CI.

\section{Gramsci e o conceito de Intelectual Orgânico}

Antonio Gramsci foi uma das referências essenciais do pensamento de esquerda no século 20, cofundador do Partido Comunista Italiano. Nasceu no ano de 1891 em Ales, na Sardenha, e morreu em 1937 algum tempo depois de deixar a prisão. Jornalista, crítico literário e político, Gramsci foi responsável por uma transformação da visão economicista do marxismo, dando importância à subjetividade humana no materialismo histórico. Escreveu os Cadernos do Cárcere durante os dez anos que esteve preso:

\footnotetext{
1 Termo criado por Johanna W. Smit para designar as três áreas vista pela autora como irmãs (Arquivologia, Biblioteconomia e Museologia).

InCID: R. Ci. Inf. e Doc., Ribeirão Preto, v. 8, n. 2, p. 92-105, set. 2017/fev. 2018.
} 
Nos cerca de dez anos que esteve no cárcere fascista (1926 - 1937), Antônio Gramsci escreveu os Cadernos do Cárcere. Sob a rigorosa censura carcerária ele não podia obter muitas informações acerca dos fatos cotidianos, o que corrigia parcialmente com um número elevado de assinaturas de revistas que se lhe permitiam ler. [...] a primeira fonte para Gramsci foi a biblioteca da prisão (SECCO, 2004, p. 217).

Em meio a repressão, acesso restrito as informações e ao acervo censurado da biblioteca, Gramsci deixou como legado uma das mais notáveis obras da história do marxismo, os cadernos do cárcere. Por meio deles, tentamos responder as angústias elencadas na introdução deste artigo. Nessa perspectiva, utilizamos o conceito de Intelectual Orgânico cunhado por Gramsci em suas obras: "Os intelectuais e a organização da cultura e o $2^{\circ}$ volume dos cadernos do cárcere".

Para o autor existem diversas categorias de intelectuais, dentre eles, os que nos cabe aqui abordar o Intelectual Tradicional. Os intelectuais tradicionais são aqueles formados historicamente por grupos da classe dominante, como bem observa Gruppi (1979, p. 80) acerca de Gramsci:

\footnotetext{
Hoje - diz Gramsci -, o capitalismo industrial cria essencialmente os técnicos, os cientistas ligados a produção. São esses os intelectuais orgânicos do capitalismo, isto é, ligados intimamente a função produtiva, a função da economia capitalista. Todo grupo social, quando se afirma no campo econômico deve elaborar sua própria hegemonia política e cultural - deve criar portanto, os próprios quadros, os próprios intelectuais -, encontra ao mesmo tempo intelectuais já formados pela sociedade precedente, pela formação econômica - social anterior: os intelectuais tradicionais.
}

Nesse sentido, o mundo capitalista cria seus próprios intelectuais que acabam por serem os grandes responsáveis por mediar informação para a grande maioria das pessoas. Para o autor, o tipo tradicional de intelectual é o filósofo, literato, artista e jornalista que crêem serem os verdadeiros intelectuais. No entanto, Gramsci relata que não existe o não intelectual, todo homem desenvolve uma atividade intelectual. Por meio dessa concepção, o autor rompe com a ideia de intelectual tradicional, ou seja, os pensadores que defendem os interesses da classe dominante e criam o seu próprio conceito moderno de intelectual:

O modo de ser do novo intelectual não pode mais consistir na eloquência, motor momentâneo dos afetos e das paixões, mas num imiscuir-se ativamente na vida prática, como construtor, organizador, persuasor permanente, já que não apenas orador puro - e superior, todavia, ao espírito matemático abstrato, da técnica-trabalho, eleva-se a técnica - ciência e a concepção humanista histórica, sem a qual se permanece especialista e não se chega a dirigente (GRAMSCI, 1979, p. 8)

Dessa maneira, o intelectual deixa de ser alguém necessariamente letrado (representante da classe dominante) e passa a ser aqueles que representam a vontade dos mais variados grupos ou núcleos informacionais, ou seja, o pastor, padre, o professor, o representante comunitário, o 
profissional da saúde, o músico, o jornalista, o profissional da computação, etc. Assim sendo, o referido texto pretende não só ampliar o conceito de mediador da informação para expandir as possibilidades de pesquisa na CI, como também busca entender de que maneira esses intelectuais orgânicos que medeiam informação interferem e podem promover transformações sociais.

\section{O conceito de profissional e mediadores da informação}

O conceito de mediador e profissional da informação no campo da ciência da informação (CI) tem sido associado, na literatura científica, a ideia do profissional bibliotecário, arquivista ou museólogo. Isso acontece com grande parte dos principais teóricos da CI. Le Coadic, por exemplo, em seu clássico Ciência da Informação entende por profissionais da informação:

Por profissionais da informação entendemos as pessoas, homens [...] e mulheres, que adquirem informação registrada em diferentes suportes, organizam, descrevem, indexam, armazenam, recuperam e distribuem essa informação em sua forma original ou como produtos elaborados a partir dela. (LE COADIC, 1996, p. 106.)

Como é possível observar, Le Coadic comunga com a ideia de profissional da informação como sendo aquele que organiza, indexa, armazena, recupera, distribui, ou seja, alguém que faça parte das três Marias. Não obstante, há também uma significativa literatura crítica que reflete acerca do profissional bibliotecário e suas instâncias como sua formação profissional ${ }^{2}$, seu compromisso ético, atuação e produção para o mercado ${ }^{3}$. No entanto, mesmo com toda essa produção, ainda não encontramos uma definição mais abrangente acerca do conceito de profissional da informação para podermos trabalhar em vários âmbitos sociais.

Uma das primeiras propostas que tentou promover mudanças e ampliar a participação do profissional da informação para além das unidades informacionais tradicionalmente pesquisadas na área de CI foi a partir do surgimento do conceito de mediação da informação. No entanto, mesmo com o aparecimento desse novo conceito ainda foi possível encontrar algumas restrições, como pode ser observado na definição feita por Almeida Junior (2009, p. 46):

\footnotetext{
${ }^{2}$ Ver artigo de César Augusto Castro intitulado: Ciência da informação e biblioteconomia: múltiplos discursos, aborda de forma crítica a necessidade de formar profissionais reflexivos em um mundo globalizado.

${ }^{3}$ Ver livro organizado por Marta Valentim intitulado: $O$ profissional da informação: formação, perfil e atuação profissional, cujos artigos de José augusto Guimarães, Marta Valentim e Oswaldo Almeida Junior retratam respectivamente as problemáticas evidenciadas acima.
}

InCID: R. Ci. Inf. e Doc., Ribeirão Preto, v. 8, n. 2, p. 92-105, set. 2017/fev. 2018. 
Mediação da informação é toda ação de interferência - realizada pelo profissional da informação -; direta ou indireta; consciente ou inconsciente, singular ou plural, individual ou coletiva; que propicie a apropriação da informação que satisfaça, plena ou parcialmente, uma necessidade informacional.

Percebe-se que o conceito de mediação proposto pelo autor amplia a concepção de profissional da informação. No entanto, a ideia de profissional ainda parece estar presa à noção do profissional das três Marias. Um pesquisador que queira analisar uma unidade informacional que não seja as tradicionalmente pesquisadas pela CI, como uma prisão, por exemplo, será desestimulado a utilizar o conceito de mediação, mesmo que esse carregue consigo os preceitos fundamentais de "interferência" e "apropriação", pois ainda está atrelada à ideia já posta de profissional da informação.

Em artigo posterior intitulado "Mediação da informação e múltiplas linguagens", Almeida Junior define com maior precisão o conceito deixando claro que o usuário interfere e interage com a informação:

\begin{abstract}
A mediação da informação permite e exige concepção de informação que desloque o usuário da categoria de mero receptor, colocando-o como ator central do processo de apropriação. Dessa forma, defendemos que o usuário é quem determina a existência ou não da informação. A informação existe apenas no intervalo entre o contato da pessoa com o suporte e a apropriação da informação. Como premissa, entendemos a informação a partir da modificação, da mudança, da reorganização, da reestruturação, enfim, da transformação do conhecimento. Assim entendida, ela, informação, não existe antecipadamente, mas apenas na relação da pessoa com o conteúdo presente nos suportes informacionais. Estes são concretos, mas não podem prescindir dos referenciais, do acervo de experiências e do conhecimento de cada pessoa. Em última instância, quem determina a existência da informação é o usuário, aquele que faz uso dos conteúdos dos suportes informacionais. (ALMEIDA JUNIOR, 2009, p. 97)
\end{abstract}

Contudo, ainda encontramos problemas para desenvolver pesquisa com outros núcleos informacionais, pois normalmente não definimos um fiel, um torcedor ou um enfermeiro como sendo um usuário, já que o termo não carrega consigo essa abrangência. Nesse sentido, mesmo com toda produção científica de extrema qualidade acerca do profissional da informação e dos mediadores informacionais, as definições necessitam de expansão.

Em capítulo de livro publicado em 2015, Almeida Junior atualizou o conceito de mediação da informação mantendo ideias anteriores como "interferência e apropriação da informação" e reiterando que a mediação deve ser entendida como um processo, na ambiência de equipamentos informacionais e que satisfaz parcial e momentaneamente uma necessidade informacional: 
Toda ação de interferência - realizada em um processo, por um profissional da informação e na ambiência de equipamentos informacionais -, direta ou indireta; consciente ou inconsciente; singular ou plural; individual ou coletiva; visando a apropriação de informação que satisfaça, parcialmente e de maneira momentânea, uma necessidade informacional, gerando conflito e novas necessidades informacionais. (ALMEIDA JÚNIOR, 2015, p. 25)

Almeida Junior reformulou o conceito e trouxe importantes contribuições à concepção de mediação, como por exemplo, a noção de "ambiência de equipamentos informacionais" que difere de ambiente físico, contemplando os ambientes de vida cotidiana dos usuários, como o trabalho, lazer, etc. Tal contribuição se aproxima da concepção de mediador que estamos tentando elucidar neste texto.

É importante salientar que Bicheri em sua dissertação: “A mediação do bibliotecário na pesquisa escolar face a crescente virtualização da informação" apresentou em determinado momento ideia ampla de mediação, relatando que a informação é mediada em todos a âmbitos da sociedade e não se restringe a uma determinada atividade ou a, apenas, um tipo de profissional:

Os mediadores e a mediação não estão restritos a uma categoria profissional e nem a uma atividade específica. O mediador pode ser o professor, um padre, um pastor, um escritor, um jornalista, um apresentador de TV ou rádio, um bibliotecário, um crítico de cinema, entre outros. Cada mediador tem sua importância. Os mediadores do conhecimento favorecem a interação entre pessoa e objeto do conhecimento, propiciando a construção, divulgação, disponibilização e reconstrução do conhecimento. Tais mediadores podem se dividir em incontáveis profissões nos diferentes estratos sociais e culturais de uma comunidade, seja ela letrada ou popular. (BICHERI, 2008, p. 94)

A definição de Bicheri, assim como o conceito apresentado por Almeida Junior em 2015, vem ampliar o conceito de mediador da informação o que pode conseguir fomentar pesquisas dentre da CI em múltiplos ambiências que ultrapassam os tradicionais estoques de informação. De forma mais abrangente, Jonhatas Silva analisou a importância da mediação para a CI e as percepções conceituais de mediação da informação desenvolvidas na área relatando que a "[...] mediação é um construto social que se estabelece entre o ser e o mundo aproximando a teoria (conhecimento) da prática (ação) [...] com vistas a transformação da realidade do(s) ser(es)" (SILVA, 2015, p. 102). Para o autor, a mediação constitui papel central nos estudos em CI, pois além de conferir novas aplicabilidades e percepções conceituais ao campo, permite pensar a atuação em centros de informação, assuntos epistemológicos e demais questões pertinentes à área.

Essas bases conceituais da mediação da informação são apresentadas por Almeida Junior como pertencentes a margem esquerda da $\mathrm{CI}$ :

InCID: R. Ci. Inf. e Doc., Ribeirão Preto, v. 8, n. 2, p. 92-105, set. 2017/fev. 2018. 
A mediação da informação tem suas bases conceituais em concepções que se localizam na margem esquerda do pensar biblioteconômico e da Ciência da Informação. Seu compromisso com as necessidades, desejos e interesses das classes populares fica talvez não de todo explícito, mas é percebido quando se conhece a estranheza com que lida com os conceitos de Sociedade da Informação, Sociedade do Conhecimento ou Sociedade da Informação e do Conhecimento; quando se conhece o emprego do termo "apropriação da informação" e não de "uso da informação"; quando afirma que a informação não dirime dúvidas, não cobre lacunas cognitivas, mas gera conflitos e tais conflitos exigem novas informações, assim, a informação gera novas necessidades, desejos, interesses; quando nos deparamos com questionamentos feitos ao próprio objeto da Biblioteconomia e Ciência da Informação (ALMEIDA JUNIOR, 2015, p. 142).

Dessa maneira, o escopo do pensar acerca da mediação da informação, ou seja, questionar termos amplamente utilizados pela área como, por exemplo, "sociedade da informação" em que carrega a ideia de que a maioria da população está contemplada por uma suposta sociedade que vive imersa e se apropria da informação, e ou o compromisso em atender as demandas das classes populares, faz com que o processo reflexivo apresente um mediador da informação eminentemente vinculado com os interesses da maioria da população. Nessa medida, a ausência de interesse dos mediadores da informação pelas classes populares é um dos motivos que vem sendo apontado, há décadas, por Almeida Junior (1995) para que o profissional bibliotecário seja entendido como improdutivo, passivo, guardião do passado, ocioso, inútil e sem função social, pois reproduz a ideologia dominante e colabora na sustentação e preservação das ideias e dos interesses das classes que detêm o poder, distanciando tanto as classes abastadas do espaço da biblioteca pública que o consideram não necessário para a sociedade capitalista, quanto as classes trabalhadoras que não se sentem representadas em seu acervo. Uma opção de aproximação das classes populares sugeridas pelo autor seria disponibilizar a população: “[...] informações que interfiram e tornem transparente o jogo de poder e as relações de classes, servindo de contraponto aos meios de comunicação de massa e abrir espaço que permita a população não só consumir mas produzir cultura (ALMEIDA JUNIOR, 1995, p. 03).

Apesar de ser uma publicação de mais de duas décadas e que na sociedade atual os mecanismos de aproximação das classes populares para os centros de informação estão para além dos meios impressos, etc., a ideia de aproximar a população menos favorecida dos espaços públicos continua legítima e fundamental. $\mathrm{O}$ autor afirma que a biblioteca pública, assim como outras instituições, é antagônica, ambígua e contraditória, pois pode tanto ter uma ação conservadora como revolucionária, porém quem determina seus caminhos e opções é o bibliotecário. 
Nesse sentido, e exaltando o fato de que o mediador da informação é capaz de, muitas vezes, determinar caminhos tomados pelas unidades de informação, a contribuição do conceito de intelectual orgânico para que possamos pensar a atuação do profissional da informação é fundamental, pois além de ampliar a ideia de que os mediadores da informação podem pertencer aos mais variados grupos sociais e não precisam ser letrados, ainda traz a ideia do mediador como sendo um agente capaz de promover significativas transformações sociais.

\section{Algumas considerações acerca do Intelectual Orgânico como Mediador da Informação}

A necessidade de interpretarmos o mundo, também, a partir de uma perspectiva vinculada à questão do trabalho humano e da reprodução das desigualdades promovidas pelo mundo capitalista, não é algo que se perdeu no século XX. A atualidade dessa temática nos faz pensar a respeito das novas circunstâncias do capitalismo desse século, como bem observa Del Roio (2005, p. 19):

[...] a atualidade do trabalho humano e da reconstituição do proletariado como classe mantem-se nas circunstâncias do capitalismo do século XXI, embora despida da tendência identitária e particularista predominante nas fases anteriores, o que mostrou ser o principal empecilho a uma perspectiva de auto-emancipação.

Nessa perspectiva, podemos refletir acerca do trabalho humano e da importância dos intelectuais como fundamentais mediadores da informação no mundo capitalista do século XXI e essenciais elementos para transformar ou manter a sociedade atual. Para Gramsci o mundo capitalista cria os seus próprios intelectuais tradicionais, ou seja, aqueles provenientes principalmente de pequenos estratos da pequena e média burguesia urbana e rural:

Deve-se notar que a elaboração de camadas intelectuais na realidade concreta não ocorre num terreno democrático abstrato, mas segundo processos históricos tradicionais muito concretos. Formaram-se camadas que, tradicionalmente, produzem intelectuais; e eles são as mesmas que, com freqüência, especializaram-se na poupança, isto é, a pequena e média burguesia fundiária e alguns estratos da pequena e média burguesia urbana. (GRAMSCI, 2001, p. 20)

Essa sociedade influenciada por intelectuais tradicionais que não pretendem promover qualquer alteração nas formas desiguais de relações estabelecidas historicamente, tende a reproduzir constantemente os mesmos intelectuais que foram e continuam a ser assimilados pelo grupo de intelectuais tradicionais. Sabendo que o desenvolvimento orgânico das massas, até certo

InCID: R. Ci. Inf. e Doc., Ribeirão Preto, v. 8, n. 2, p. 92-105, set. 2017/fev. 2018. 
ponto, depende dos movimentos de intelectuais, Gramsci propôs a ideia ampla de intelectual, segundo a qual, todos os homens são intelectuais. Para o autor toda atividade exige o mínimo de atividade intelectual criadora:

[...] o operário ou proletário, por exemplo, não se caracteriza especificamente pelo trabalho manual ou instrumental, mas por este trabalho em determinadas condições e em determinadas relações sociais (sem falar no fato de que não existe trabalho puramente físico, e de que mesmo a expressão de Taylor, do "gorila amestrado", é uma metáfora para indicar o limite numa certa direção: em qualquer trabalho físico, mesmo no mais mecânico e degradado, existe um mínimo de qualificação técnica, isto é, um mínimo de atividade intelectual criadora). E já se observou que o empresário, pela sua própria função, deve possuir em certa medida algumas qualificações de caráter intelectual, embora sua figura intelectual seja determinada não por elas, mas pelas relações sociais gerais que caracterizam efetivamente a posição do empresário na indústria. (GRAMSCI, 2001, p.18)

Nesse sentido, Gramsci nos apresenta a possibilidade de rompermos com a ideia tradicional de intelectual restrita àquela do filósofo, literato, artista e jornalista que crêem serem os verdadeiros intelectuais, e revela a necessidade dos vários grupos sociais terem os seus próprios intelectuais. A partir dessa visão podemos entender o profissional e o mediador da informação em uma dimensão ampla, não apenas aqueles tradicionalmente pesquisados pela CI (bibliotecário, arquivista, museólogo), mas aos mais variados ambientes informacionais.

Dessa maneira, entendemos o conceito de profissional e o mediador da informação como sendo um intelectual orgânico oriundo de diversos ambientes, ou seja, todos aqueles que pertençam a múltiplos núcleos informacionais e que medeiam informação à sociedade.

Assim sendo, por meio dessa concepção, além de ampliarmos a ideia de mediadores da informação, ainda colocamos esses como protagonistas sociais, como bem observa Gomes (2014) acerca da atividade dos mediadores: "O profissional da mediação da informação age, constrói e interfere no meio, portanto, é também um protagonista social, e nessa condição se constitui em sujeito da estética, da ética e da produção humanizadora do mundo" (GOMES, 2014, p. 47.). 


\title{
5. Intelectual Orgânico e a Ciência da Informação: um diálogo possível
}

Ao analisar o conceito de mediação da informação na área de CI, Almeida (2007) acredita que o campo generalizou o entendimento da ideia de mediação vinculando-a à noção de "servir de intermediário" e dessa maneira o profissional da informação cumpriria o papel apenas de mediador. Não obstante, o autor deixa claro que a ideia de mediação abarca uma gama de atividades envolvendo desde o tradicional "atendimento ao usuário" à “elaboração de política de capacitação ou acesso às tecnologias de informação e comunicação”.

Essa perspectiva revela o quão fundamental é refletirmos acerca da mediação, tanto para averiguar as possibilidades de atuação do profissional no campo, como para expandir as possibilidades ou extrapolar os limites da área. Almeida (2007) questiona a proliferação de um profissional da informação com perfil puramente técnico:

\begin{abstract}
Se hoje soa utópico ou ingênuo pensar num perfil de profissional da informação como "intelectual orgânico" em função da série de mudanças pelas quais passou o mundo contemporâneo e o Brasil em particular, tampouco vale apontar para um perfil "técnico" que, na sua aparente neutralidade, escamoteia questões sociais e políticas relevantes. A inserção dos profissionais de informação nos processos culturais atentando para sua função de construção da hegemonia parece-me, nesse sentido, um dos focos a ser privilegiado numa formação que se quer crítica (ALMEIDA, 2007, p. 13).
\end{abstract}

Esse perfil de profissional "técnico" e de "aparente neutralidade" acaba por ser bastante disseminado e integrado aos currículos dos cursos da área por atender as demandas de mercado. Tal fato pode trazer sérias consequências à área, como revela Araújo (2013) que ao tentar compreender a ausência de manifestação crítica e de diálogo social do campo, aponta para a tradição custodial, tecnicista e acrítica que esteve no escopo das disciplinas fundadoras da CI, antes mesmo dela se constituir como campo de pesquisa.

Essa postura acabou por promover prioridades técnicas nos cursos de biblioteconomia e arquivologia, o que dificultou a relação mais efetiva dos profissionais da área com a sociedade. Araújo (2013) relata que falta a CI encontrar-se com as possibilidades de utopia e fazer-se, então, práxis.

Talvez o que falte nesse momento para a Ciência da Informação, em tempos de crise das utopias, dos projetos políticos e mesmo dos projetos de inclusão e democratização informacional; com projetos voltados para uma dimensão essencialmente técnica, à maneira mesma de uma "engenharia social"; e com leituras muitas vezes apenas instrumentais da atuação da área e dos profissionais por ela formados; seja engajar-se na proposta de construção de uma "imaginação informacional". Para, então, sem deixar de

InCID: R. Ci. Inf. e Doc., Ribeirão Preto, v. 8, n. 2, p. 92-105, set. 2017/fev. 2018. 
lado a crítica ideológica e a desconfiança dos discursos sobre o momento contemporâneo, reencontrar-se com as possibilidades da utopia e fazer-se, então, práxis (ARAUJO, 2013, p. 118).

Dessa forma, por mais que pareça utópico ou ingênuo, como relatou Almeida (2007), pensar o perfil profissional da informação ou do mediador da informação como intelectual orgânico, a área padece com a ausência de manifestação crítica e esse diálogo possível com a CI nos parece essencial para que o mediador da informação possa romper com os limites que o separam da sociedade e promover significavas transformações sociais.

\section{Considerações finais}

Tentamos retratar nesse breve texto as restrições do conceito de profissional da informação que vem inibindo o desenvolvimento de pesquisas que abordem os novos ambientes informacionais que entendemos serem essenciais para melhor compreender a circulação da informação na sociedade, e, além disso, demonstrar como essas populações (instituições e grupos sociais) são postas a margem de pesquisas na área da $\mathrm{CI}$.

Importante salientar que seria interessante narrar a trajetória dos arquivos, bibliotecas e museus mostrando como essas instituições surgiram na Europa, com o avento da modernidade, se desenvolveram no século XIX em um contexto positivista, acabaram por priorizar os acervos guardados (tradição custodial), e mantiveram acesso a grupos restritos da sociedade, atendendo em muitos casos os anseios da elite da época (SILVA, 2002; BURKE, 2003; ARAUJO, 2011; SMIT, 2002). Anseios da elite que também foram atendidos ao longo do desenvolvimento da história das instituições brasileiras (MILANESI, 2002; CASTRO, 2000; ALMEIDA JUNIOR, 2015), traços que se perpetuaram em muitas instituições na contemporaneidade. No entanto, tal empreendimento seria um trabalho de bastante fôlego e é uma possibilidade em aberto, um desafio para o futuro.

Dessa forma, e com objetivo de romper com a trajetória de atender apenas aos anseios de um restrito grupo social, a ideia do intelectual orgânico como mediador da informação traz elementos fundamentais para analisarmos a informação mediada nos mais variados núcleos informacionais, como nos presídios, nas igrejas, escolas, hospitais, estádios de futebol, meios de comunicação, partidos, estúdios, domicílios, centros culturais, bares, manicômios, etc. Dessa maneira, os mediadores podem ser uma infinidade de pessoas letradas ou não, como: o pastor, o 
padre, o jogador, o representante comunitário, o professor, o profissional da saúde, o músico, o jornalista, o trabalhador da indústria, o motorista, o cobrador de ônibus, etc.

Conceber o mediador da informação a partir da concepção Gramsciana de intelectual orgânico não só amplia a ideia de mediação da informação e a possibilidade de desenvolver novas pesquisas nos inúmeros núcleos informacionais, como também deixa a ideia de que todos são intelectuais e agentes mediadores da informação e não apenas um restrito intelectual tradicional, ou seja, um profissional letrado (o filósofo, literato, artista e jornalista) que crêem serem os verdadeiros intelectuais, pois para Gramsci “todos os homens são intelectuais".

Portanto, para que possamos trabalhar com os múltiplos mediadores sociais e ambientes informacionais há a necessidade urgente da CI entender os profissionais e os mediadores da informação como intelectuais orgânicos, pois a partir daí poderemos compreender um pouco do possível objeto da CI (a informação ou a mediação da informação) e como esta interfere na vida das pessoas e promove transformações sociais.

\title{
Referências
}

ALMEIDA JÚNIOR, O. F. Biblioteca pública: ambiguidade, conformismo e ação guerrilheira do bibliotecário. São Paulo: APB, 1995. (Ensaios APB, n. 15).

. Mediação da informação e múltiplas linguagens. Pesquisa Brasileira em Ciência da Informação e Biblioteconomia, João Pessoa, v. 2, n. 1, p. 89-103, jan./dez.2009. Disponível em: <http://periodicos.ufpb.br/index.php/pbcib/article/view/11990>. Acesso em: 20 nov. 2016.

. Mediação da informação: um conceito atualizado. In: BORTOLIN, S.; SANTOS NETO, J. A.; SILVA, R. J. (Org.). Mediação oral da informação e da leitura. Londrina: ABECIN, 2015. p. 9-32.

. Conservadorismo e revolução (ou reformismo) na biblioteconomia e Ciência da Informação. Divers@ Revista Eletrônica Interdisciplinar, Matinhos, v. 8, n. 2, p. 132-144, jul./dez. 2015. Disponível em : < http://dx.doi.org/10.5380/diver.v8i2.45052>. Acesso em: 13 mai.2016.

\author{
ALMEIDA, M. A. Mediação cultural e da informação. ENCONTRO NACIONAL DE \\ PESQUISA EM CIÊNCIA DA INFORMAÇÃO, 8., 2007. Anais... Salvador: UFBA, 2007. \\ Disponível em: \\ <http://www.ufpb.br/evento/lti/ocs/index.php/enancib2016/enancib2016/paper/view/3513/2278>. \\ Acesso em 12 nov 2015.
}


ARAUJO, C. A. Á. Condições teóricas para a integração epistemológica da Arquivologia, Biblioteconomia e Museologia na Ciência da Informação. InCID: Revista de Ciência da Informação e Documentação, Ribeirão Preto, v. 2, n. 2, p. 19-41, dec. 2011. Disponível em: <http://www.revistas.usp.br/incid/article/view/42349>. Acesso em: 08 jun. 2017.

. Manifestações e (ausências) de pensamento crítico na Ciência da Informação. Biblos: Revista do Instituto de Ciências Humanas e da Informação, Rio Grande, v. 27, n. 2, p. 9-29, jul./dez. 2013. Disponível em: 〈https://www.seer.furg.br/biblos/article/viewFile/3364/2750>. Acesso em: 14 ago. 2016.

BICHERI, A. L. A. O. A mediação do bibliotecário na pesquisa escolar face a crescente virtualização da informação. Dissertação (Mestrado em Ciência da informação) - Faculdade de Filosofia e Ciências, Universidade Estadual Paulista, Marília, 2008.

BURKE, P. Uma história social do conhecimento: de Gutemberg a Diderot. Rio de Janeiro: Jorge Zahar, 2003.

CASTRO, C. A. História da Biblioteconomia brasileira: perspectiva histórica. Brasília: Thesaurus, 2000.

DEL ROIO, M. Os prismas de Gramsci: a fórmula política da frente única (1919 - 1926). São Paulo: Xamã, 2005.

GOMES, H. F. A dimensão dialógica, formativa e ética da mediação da informação. Informação \& Informação, Londrina, v. 19, n. 2, p. 46-59, maio/ago. 2014. Disponível em: <http://www.uel.br/revistas/uel/index.php/informacao/article/view/19994/19090 >. Acesso em: 19 nov. 2016.

GRAMSCI, A. Cadernos do cárcere. Rio de Janeiro: Civilização Brasileira, 2001. 3 v.

Os intelectuais e a organização da cultura. 3. ed. Rio de Janeiro:[s.n.], 1979.

GRUPPI, L. Conceito de hegemonia em Gramsci. Rio de Janeiro: Graal, 1979.

LE COADIC, Y. F. A ciência da informação. Brasília: Briquet de lemos, 1996.

MILANESI, L. Biblioteca. São Paulo: Ateliê Cultural, 2002.

SECCO, L. Biblioteca Gramsciana: os livros da prisão de Antônio Gramsci. Revista de História, v. 150, n. 1, p. 209-228, 2004. Disponível em: <http://www.revistas.usp.br/revhistoria/article/view/18983>. Acesso em: 12 out. 2016.

SILVA, A. B. M. Arquivística, Biblioteconomia e Museologia: do empirismo patrimonialista ao paradigma emergente da Ciência da Informação. São Paulo: Imprensa Oficial do Estado de SP, 2002. 
SILVA, J. L. C. Percepções conceituais sobre mediação da informação. InCID: Revista de Ciência da Informação e Documentação, Ribeirão Preto, v. 6, n. 1, p. 93-108, abr. 2015. Disponível em: 〈http://www.revistas.usp.br/incid/article/view/89731>. Acesso em: 01 abr. 2017.

SMIT, J. W. Arquivologia, Biblioteconomia e Museologia: o que agrega estas atividades profissionais e o que as separa? Revista Brasileira de Biblioteconomia e Documentação, Brasília, v. 1, p. 27-36, 2002. Disponível em:

<https://rbbd.febab.org.br/rbbd/article/viewFile/399/373>. Acesso em: 10 out. 2015.

VALENTIM, M. L. P. Atuação profissional na área de informação. São Paulo: Polis, 2004. (Coord.). Formação do profissional da informação: formação: competências e habilidades do profissional da informação. São Paulo: Polis, 2002. 